\title{
Time-Domain Modeling of Tower Shadow and Wind Shear in Wind Turbines
}

\author{
Swagata Das, Neeraj Karnik, and Surya Santoso \\ Department of Electrical and Computer Engineering, The University of Texas at Austin, Austin, TX 78712, USA \\ Correspondence should be addressed to Surya Santoso, ssantoso@ece.utexas.edu
}

Received 11 July 2011; Accepted 31 July 2011

Academic Editors: W. E. Alnaser, M. Cheng, S. S. Kalligeros, and B. Mwinyiwiwa

Copyright () 2011 Swagata Das et al. This is an open access article distributed under the Creative Commons Attribution License, which permits unrestricted use, distribution, and reproduction in any medium, provided the original work is properly cited.

Tower shadow and wind shear contribute to periodic fluctuations in electrical power output of a wind turbine generator. The frequency of the periodic fluctuations is $n$ times the blade rotational frequency $p$, where $n$ is the number of blades. For three-bladed wind turbines, this inherent characteristic is known as the $3 p$ effect. In a weak-power system, it results in voltage fluctuation or flicker at the point of common coupling of the wind turbine to the grid. The phenomenon is important to model so as to evaluate the flicker magnitude at the design level. Hence, the paper aims to develop a detailed time-domain upwind fixed speed wind turbine model which includes the turbine's aerodynamic, mechanical, electrical, as well as tower shadow and wind shear components. The model allows users to input factors such as terrain, tower height, and tower diameter to calculate the $3 p$ oscillations. The model can be expanded to suit studies involving variable speed wind turbines. Six case studies demonstrate how the model can be used for studying wind turbine interconnection and voltage flicker analysis. Results indicate that the model performs as expected.

\section{Introduction}

In addition to the stochastic pulsations caused by wind, electrical power output from wind turbines connected to the power system grid experience short-term fluctuations at $n$ times the rotational frequency of the blades $(p)$ or $n p$ frequency, where $n$ is the number of blades. Wind turbines generally have three blades and hence this is known as the $3 p$ effect. The $3 p$ fluctuations are due to two effects known as wind shear and tower shadow $[1,2]$. Wind shear refers to the variation of wind with height while tower shadow is used to describe the redirection in wind due to the obstruction presented by the tower $[1,3]$. These two effects are an inherent characteristic of any wind turbine and will result in periodic fluctuations in output power.

For wind turbines connected to a weak grid, the $3 p$ frequency in the range of $0.5-2 \mathrm{~Hz}$ results in fluctuations in system rms voltage at the point of common coupling (PCC) and are known as voltage flicker or fluctuations $[4,5]$. In a system with significant wind generation wherein wind farms supply majority of the power to the grid, synchronization of the blades in the wind farm contribute to larger power and voltage fluctuations [2]. From a consumer perspective, voltage flicker is a serious power quality issue [6] and hence wind turbine models have become indispensable for wind power interconnection study. Using such a model, the designer of the wind turbine must be capable of calculating at the design stage, the expected flicker magnitude and whether the flicker is below the threshold of objection [6]. The designer must also be able to assess the dependence of voltage flicker on wind speed, grid characteristics, as well as the loads connected at the PCC [4]. Many papers on wind power integration have been reported in the literature $[4,7,8]$. Due to their focus on voltage flicker and other power quality issues, these models often tend to oversimplify the torque considerations due to tower shadow and wind shear. They do not factor in wind turbine specifications such as hub height, tower diameter, and terrain on which the wind turbine is located which affect the magnitude of tower shadow and wind shear. These parameters should be an input to the wind turbine simulation model, offering insight into the wind turbine parameters which can be optimized to reduce $3 p$ oscillations at the design level. Other papers oversimplify wind turbine operation and rotor performance characteristics [9]. 
Based on the aforementioned background, the objective of this paper is to develop a detailed time-domain wind turbine model upon which more sophisticated models can be developed. The paper focuses on modeling a fixedspeed wind turbine with an upwind rotor since they are most common due to reduced tower shading $[1,10]$. The paper builds upon the most basic model of a fixed-speed wind turbine developed in [11] and includes the turbine's aerodynamic, mechanical, electrical, as well as tower shadow and wind shear components. The complete model can be easily implemented in popular simulation packages such as PSCAD/EMTDC and MATLAB. Since the model has been broken down into blocks/modules and each module is separately quantified, the model is flexible, allowing users to separately study the impact of wind shear and tower shadow on output power. The model can also be used to study the wind turbine integration to the grid, voltage flicker analysis, mitigation techniques of $3 p$ effects, and expanded to suit studies involving variable speed wind turbines.

The paper is organized as follows: Sections 2 and 3 study the modeling and identifies the factors affecting wind shear and tower shadow. Section 4 discusses the comprehensive modeling of the wind turbine. Section 5 presents six case studies to evaluate the validity of the model along with the dataset used in simulating the wind turbine so that it can be easily reproduced by the users. The results are consistent with those reported in the literature and hence the model performs as expected.

\section{Wind Shear}

Wind turbine blades experience maximum wind speed when facing directly upwards and minimum when the blades are facing downwards. This variation in wind with height is known as wind shear. For three-bladed wind turbines, each of the three blades will experience minimum wind speed in one complete rotation and hence wind shear contributes to the $3 p$ frequency [1]. This section studies the wind shear model and identifies the factors which contribute to the wind shear effect.

2.1. Modeling Wind Shear. A simple wind shear model is given by the power law as $[1,3]$

$$
V(z)=V_{h}\left(\frac{z}{H}\right)^{\alpha}
$$

where $z, H, V_{h}$, and $\alpha$ are the elevation above ground, hub height, wind speed at hub height, and empirical wind shear exponent, respectively. Writing (1) as a function of $r$ (radial distance from rotor axis) and $\theta$ (blade azimuthal angle), the wind shear model becomes

$$
V(r, \theta)=V_{h}\left(\frac{r \cos \theta+H}{H}\right)^{\alpha}=V_{h}\left[1+W_{s}(r, \theta)\right]
$$

TABLE 1: Variation of $\alpha$ with terrain.

\begin{tabular}{lc}
\hline Terrain & $\alpha$ \\
\hline Smooth, hard ground, lake, or ocean & 0.10 \\
Smooth, level, grass-covered & 0.14 \\
Tall row crops, low bushes with few trees & 0.20 \\
Many trees, occasional buildings & 0.24 \\
\hline
\end{tabular}

where $W_{s}(r, \theta)$ is the disturbance in wind speed due to wind shear. It can be approximated by a third order truncated Taylor series as,

$$
\begin{aligned}
W_{s}(r, \theta) \approx & \alpha\left(\frac{r}{H}\right) \cos \theta+\frac{\alpha(\alpha-1)}{2}\left(\frac{r}{H}\right)^{2} \cos ^{2} \theta \\
& +\frac{\alpha(\alpha-1)(\alpha-2)}{6}\left(\frac{r}{H}\right)^{3} \cos ^{3} \theta
\end{aligned}
$$

2.2. Factors Affecting Wind Shear. From (2) and (3), disturbance in wind due to wind shear is dependent on $V_{h}, H, \alpha$, and $r$. Figure 1(a) shows the variation of wind shear with $V_{h}$. For $V_{h}=13.5 \mathrm{~m} / \mathrm{s}$, the maximum wind speed experienced by the blades of a wind turbine is $14.75 \mathrm{~m} / \mathrm{s}$ while the minimum wind speed is $13.04 \mathrm{~m} / \mathrm{s}$. Hence, the variation in wind speed, that is, the difference between maximum and minimum wind speed for one complete blade rotation is $1.71 \mathrm{~m} / \mathrm{s}$. Similarly for $V_{h}=14 \mathrm{~m} / \mathrm{s}$, the variation in wind speed is $1.77 \mathrm{~m} / \mathrm{s}$. Thus wind shear increases with the increase in $V_{h}$. Also note that the minimum wind speed occurs at $\theta=180^{\circ}$, that is, when the blades are pointing downwards and maximum wind speed at $\theta=0^{\circ}$, that is, blades pointing upwards. Figure 1(b) shows the impact of $\alpha$ on wind shear. The values of $\alpha$ have been chosen depending on terrain, as shown in Table 1 [12]. As $\alpha$ increases, wind shear increases. Figure 1(c) shows that wind shear decreases with increase in hub height. For example, at $H=120 \mathrm{~m}$, the variation in wind is $0.72 \mathrm{~m} / \mathrm{s}$ while at $H=80 \mathrm{~m}$, the wind variation is $1.77 \mathrm{~m} / \mathrm{s}$. Figure $1(\mathrm{~d})$ shows the wind shear experienced by different blade elements. Minimum wind shear is experienced by the blade element closest to the hub $(r=5 \mathrm{~m})$.

\section{Tower Shadow}

Tower shadow effect is the alteration in uniform flow of wind due to the presence of the tower. For an upwind turbine, when the blade is directly in front of the tower, it experiences minimum wind. For a three-bladed wind turbine, each of the blades experience minimum wind in one complete rotation and hence tower shadow contributes to the $3 p$ effect $[1,2]$. This section models tower shadow effect for an upwind turbine and identifies the factors affecting tower shadow.

3.1. Modeling the Disturbance in Wind due to Tower Shadow. Figure 2 shows an aerial view of the tower immersed in uniform wind flow. As seen from the figure, when the uniform wind is incident on the tower, it tries to bend around the tower. At the point marked as "source," the wind streamlines radiate outwards. At the point marked as "sink," 


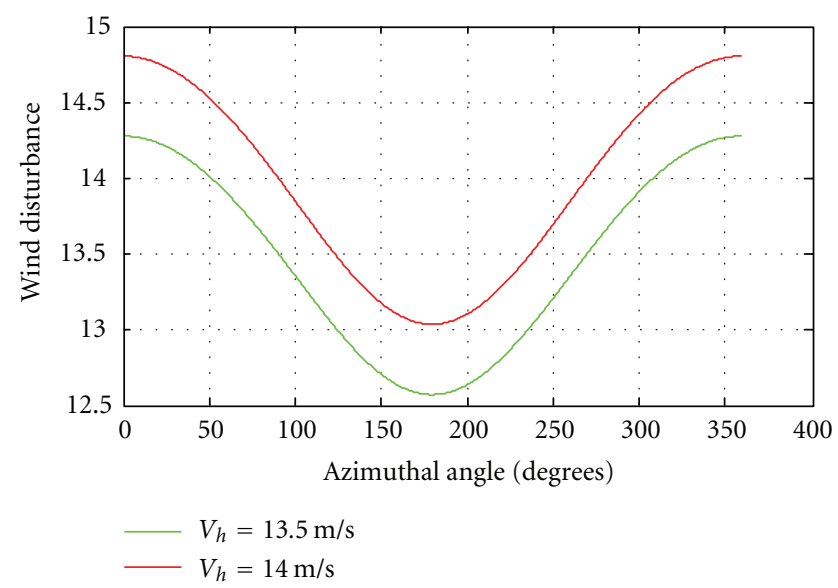

(a) Effect of wind speed $\left(V_{h}\right)$ on wind shear


(c) Effect of hub height $(H)$ on wind shear

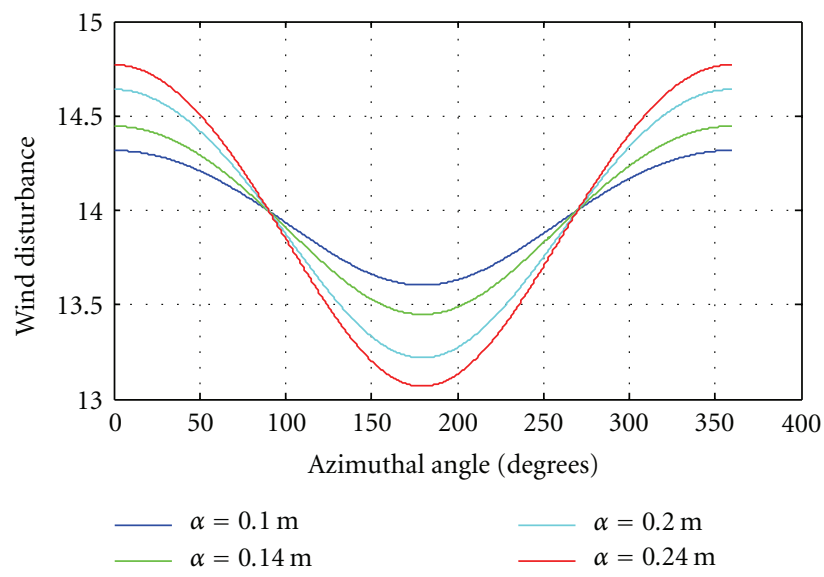

(b) Effect of terrain $(\alpha)$ on wind shear
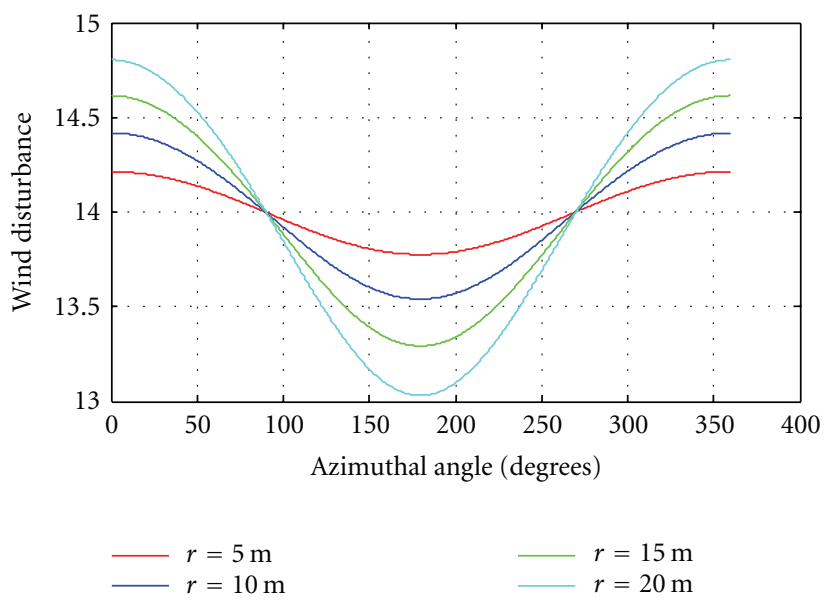

(d) Effect of radial distance ( $r$ ) on wind shear

Figure 1: Comparison of wind shear with different (a) $V_{h}$, (b) $\alpha$, (c) $H$, and (d) $r$.

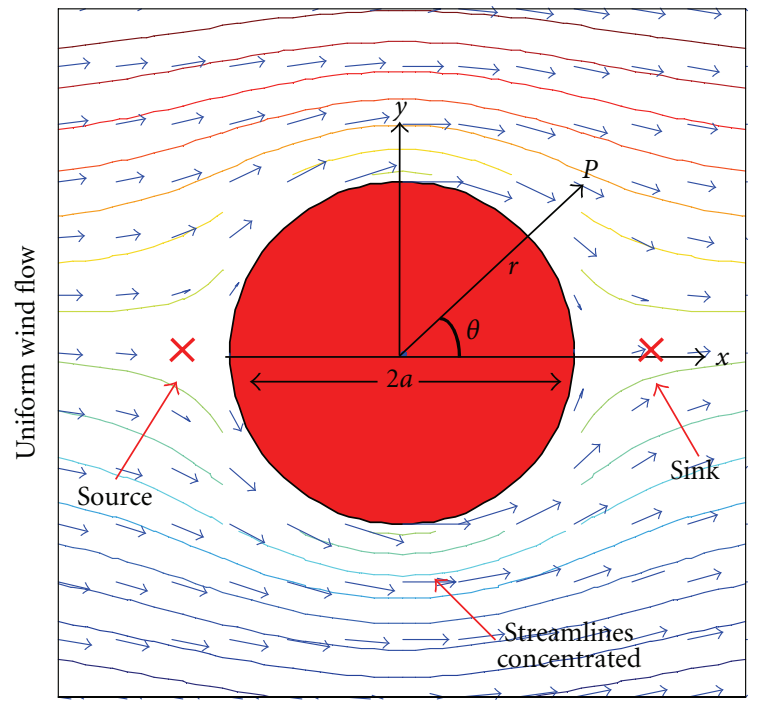

FIGURE 2: Wind flow around the tower obtained by superposing a doublet in uniform wind. the wind streamlines converge. A source and sink at very close spacing (separated only by the tower diameter) form a doublet [13].

Hence, from potential flow theory, stream function of wind around the tower can be derived by superposing a doublet on uniform flow as [13]

$$
\begin{aligned}
\psi & =\psi_{\text {uniform }}+\psi_{\text {doublet }} \\
& =V_{h} y\left(1-\frac{a^{2}}{x^{2}+y^{2}}\right) .
\end{aligned}
$$

Differentiating stream function $\psi$ with respect to $y$ yields the total wind flow velocity $V(y, x)$ in the $x$-direction as

$$
\begin{aligned}
V(y, x) & =\frac{\partial \psi}{\partial y}=V_{h}\left[1+\frac{a^{2}\left(y^{2}-x^{2}\right)}{\left(x^{2}+y^{2}\right)^{2}}\right] \\
& =V_{h}+V_{\text {tower }}(y, x) .
\end{aligned}
$$

The second term in (5), that is, $V_{\text {tower }}(y, x)$ represents the disturbance in wind due to the presence of the tower $[1,10]$. 


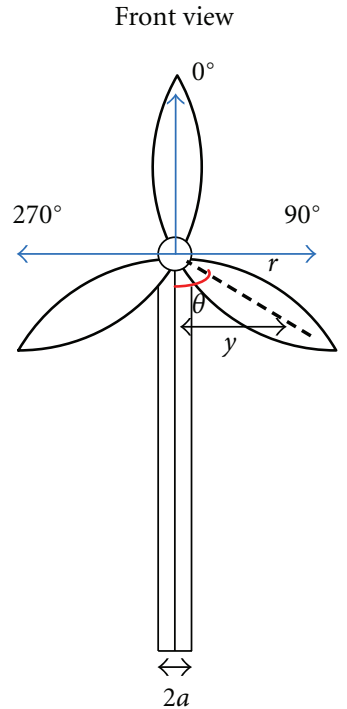

Side view

FIGURE 3: Dimensions used in tower shadow formula.

Here $a$ is the tower radius, $x$ is the distance of blade origin from the tower midline and $y$ is the lateral distance of the blade from the tower midline, as shown in Figure 3. Writing $V_{\text {tower }}(y, x)$ as a function of $r$ and $\theta$ yields

$$
V_{\text {tower }}(r, \theta, x)=V_{h} \frac{a^{2}\left(r^{2} \sin ^{2} \theta-x^{2}\right)}{\left(r^{2} \sin ^{2} \theta+x^{2}\right)^{2}} .
$$

It should be noted that (6) is valid only when the blades are in the tower shadow zone, that is, $90^{\circ} \leq \theta \leq 270^{\circ}$, as shown in Figure 3. As justified in [1], the hub height wind speed in (5) is assumed to be equal to the spatial average wind speed.

3.2. Factors Affecting Tower Shadow. From (6), the disturbance in wind due to tower-shadow effect depends on three factors, $r, \theta$, and $x$. Hence, in the first case, $r$ is varied from $5 \mathrm{~m}$ to $20 \mathrm{~m}$ in (6) while $\theta$ is varied from $90^{\circ}$ to $270^{\circ}$, that is, the tower-shadow zone, as shown in Figure 4(a). It is observed that the blade elements closest to the hub $(r=5 \mathrm{~m})$ experience a longer duration of the tower shadow. However at $\theta=180^{\circ}$, that is, blade directly in front of the tower, the same wind deficit is seen by all the blade elements.

Next, the radial distance of blade element from the hub, that is, $r$ is kept constant at $20 \mathrm{~m}$ and the distance of blade origin from the tower midline, that is, $x$ is varied from $2 \mathrm{~m}$ to $5 \mathrm{~m}$. As seen from Figure 4(b), the tower shadow effect is most pronounced when the blades are closer to the tower $(x=2 \mathrm{~m})$. Hence, mounting the blades away from the tower minimizes tower-shadow effect. Also note that there is an acceleration in wind when the blades are at either side of the tower, as seen in Figure 4. This is true since when the streamlines bend around the tower, they become concentrated on the sides of the tower, as shown in Figure 2, resulting in an acceleration of wind.

\section{Time-Domain Modeling of Wind Turbines}

From a modeling standpoint, the primary components of a wind turbine consist of turbine rotor (prime mover), shaft and gearbox unit (drive-train and speed changer), induction generator, and a control system [11]. Wind turbines extract the kinetic energy available in winds and convert it to electrical energy and hence require interaction between aerodynamic, mechanical, and electrical components, as illustrated in Figure 5. The modeling of these four building blocks are discussed in this section.

4.1. Aerodynamic Block. The aerodynamic block consists of six modules.

(i) Tip-speed ratio calculation $\lambda_{0}$.

(ii) Pitch-angle determination $\beta$.

(iii) Rotor power coefficient $C_{p}\left(\lambda_{0}\right)$.

(iv) Aerodynamic torque module.

(v) Torque due to wind shear.

(vi) Torque due to Tower Shadow.

The modeling of the first three modules have been discussed in details in [11]. This subsection discusses the modeling of the aerodynamic torque module and the two additional blocks on torque due to wind shear and tower shadow. Note that the input to the aerodynamic block is the hub height wind speed $\left(V_{h}\right)$ which can be set to any value during simulation run-time or can also be in the form of time-series data of an actual wind speed measurement [11].

4.1.1. Torque Computation. The wind turbine experiences a relatively constant hub height wind speed $V_{h}$. However, due to tower shadow and wind shear, the blades of a wind turbine experience a varying wind speed as it rotates through a complete cycle, as seen in Sections 2 and 3. Hence the approach to formulating a pragmatic torque equation incorporating the $3 p$ effect is to first derive the total spatially varying wind field, which includes the contribution from tower shadow and wind shear, and then compute the resultant aerodynamic torque [1]. The approach is briefly summarized below.

The total wind experienced by the wind turbine blades due to tower shadow and wind shear is

$$
v(t, r, \theta) \approx V_{h}\left[1+W_{s}(r, \theta)+\frac{V_{\text {tower }}(r, \theta, x)}{V_{h}}\right],
$$

where $W_{s}(r, \theta)$ and $V_{\text {tower }}(r, \theta, x)$ are given by (3) and (6). Next, the total aerodynamic torque produced by a threebladed wind turbine when immersed in a wind field of $v(t, r, \theta)$ is,

$$
\begin{aligned}
T_{\text {aero }}(t, \theta)=\frac{1}{2} & \frac{\rho A V_{h}^{3} C_{p}\left(\lambda_{0}\right)}{\omega_{\text {rotor }}} \\
& +\sum_{b=1}^{3} \int_{r_{0}}^{R} \frac{2 \rho A V_{h} C_{p}\left(\lambda_{0}\right)}{3 s R \lambda_{0}} r\left[v(t, r, \theta)-V_{h}\right] d r,
\end{aligned}
$$




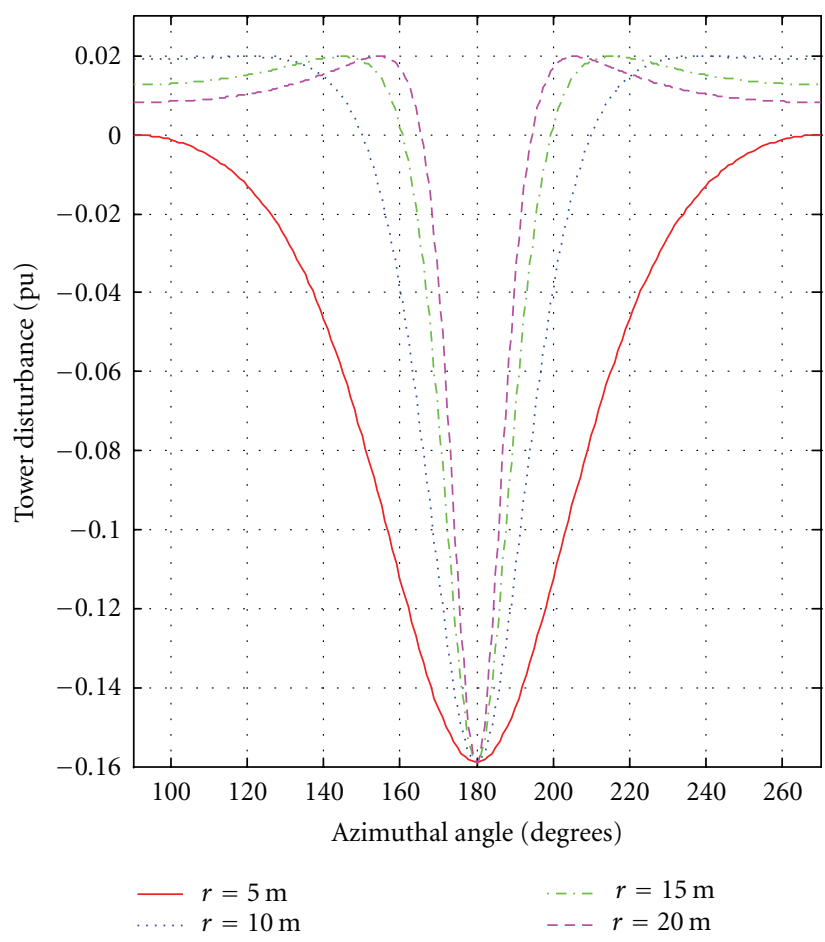

(a) Effect of radial distance $(r)$ on tower shadow

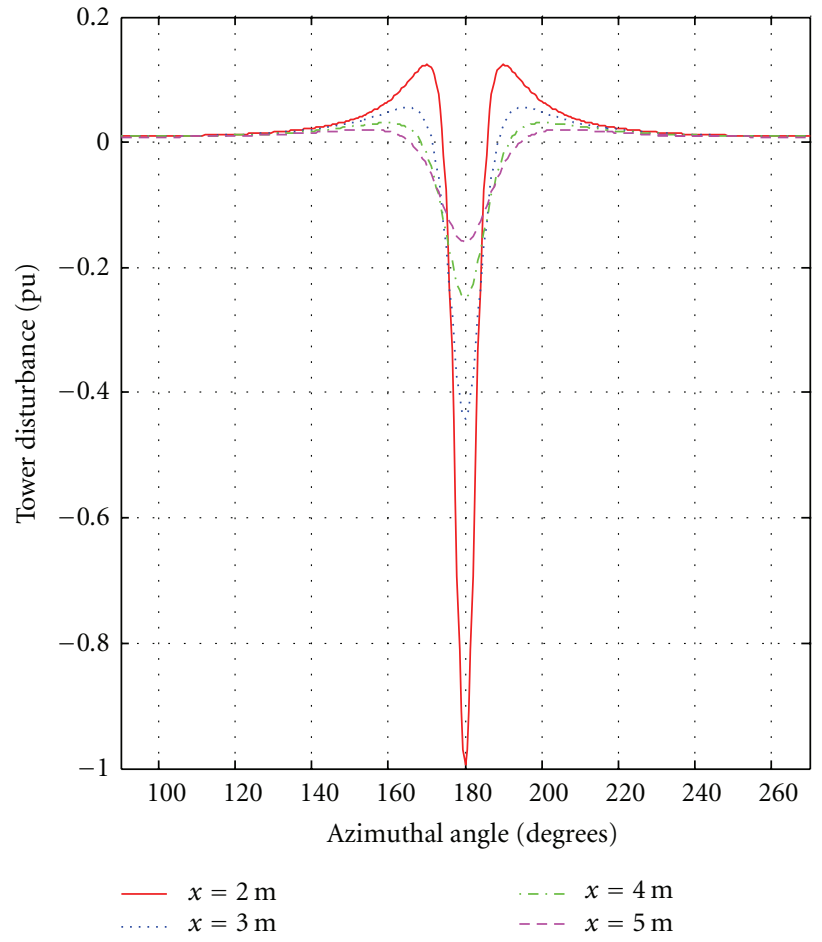

(b) Effect of lateral distance from tower midline $(x)$ on tower shadow

FiguRE 4: Comparison of tower shadow at different (a) radial distances $r$ and (b) lateral distances from tower midline $x$.

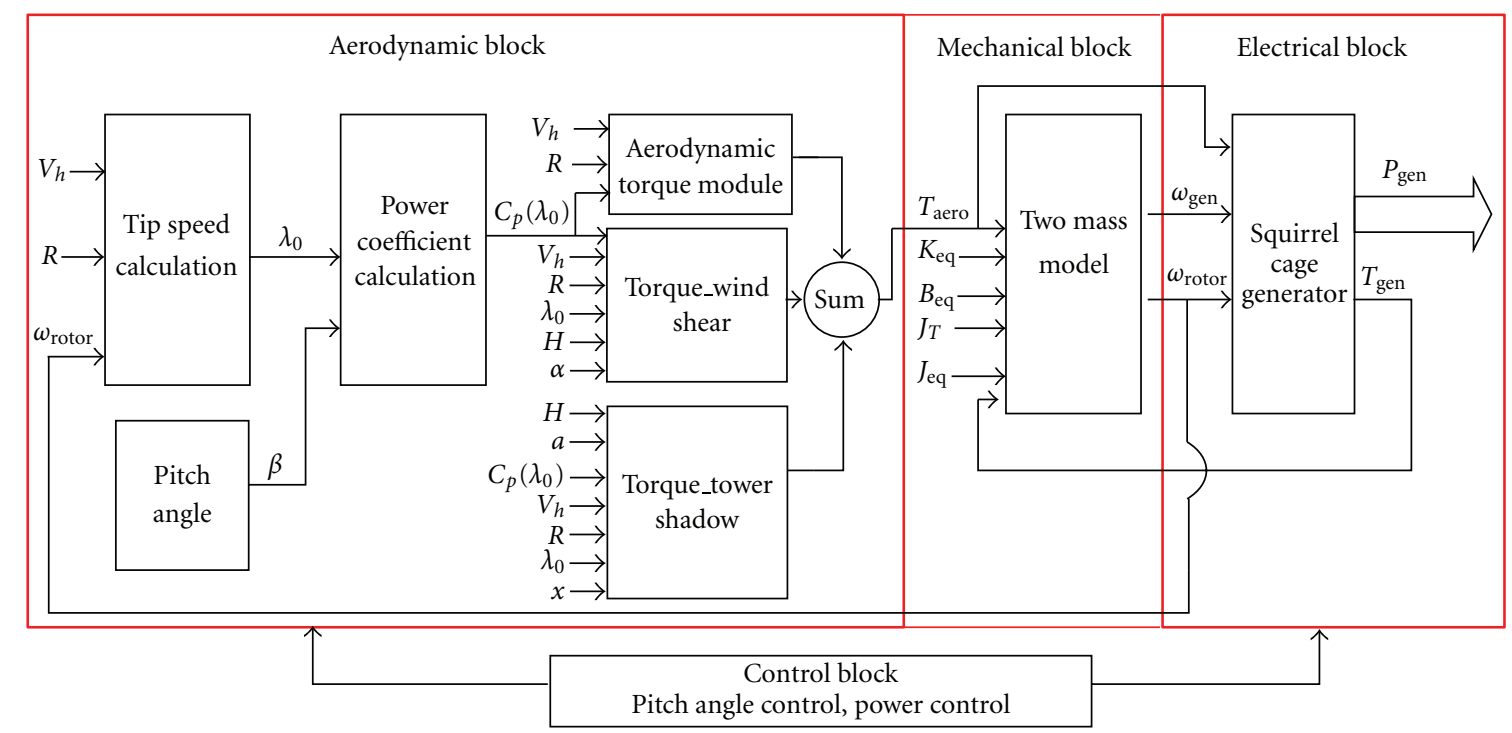

FIGURE 5: Block diagram of a wind turbine.

where $T_{\text {aero }}(t, \theta)$ is the aerodynamic torque, $r_{0}$ the radius at which the blade profile begins, $R$ the radius of the rotor disk, $A$ is the cross-sectional area of rotor, $\rho$ is the air density, $\omega_{\text {rotor }}$ is the rotor angular velocity, and $s$ is defined to be equal to $1-\left(r_{0} / R\right)^{2}$. This equation has been obtained by linearizing the classical torque equation about the hub height wind speed $[1,10]$. To remove the radial dependence in $v(t, r, \theta)$, [10] defines an equivalent wind speed $v_{\mathrm{eq}}(t, \theta)$, which would give rise to the same aerodynamic torque $T_{\text {aero }}(t, \theta)$, such that,

$$
\begin{aligned}
T_{\text {aero }}(t, \theta)=\frac{1}{2} & \frac{\rho A V_{h}^{3} C_{p}\left(\lambda_{0}\right)}{\omega_{\text {rotor }}} \\
& +\sum_{b=1}^{3} \int_{r_{0}}^{R} \frac{2 \rho A V_{h} C_{p}\left(\lambda_{0}\right)}{3 s R \lambda_{0}} r\left[v_{\mathrm{eq}}(t, \theta)-V_{h}\right] d r .
\end{aligned}
$$


Equating (8) and (9) and simplifying, the expression for equivalent wind speed is obtained as

$$
\begin{gathered}
v_{\mathrm{eq}}(t, \theta) \\
=\frac{2 V_{h}}{3 s R^{2}} \sum_{b=1}^{3} \int_{r_{0}}^{R}\left[r+r^{2}\left(\frac{\alpha}{H}\right) \cos \theta_{b}+\frac{r^{3} \alpha(\alpha-1)}{2 H^{2}} \cos ^{2} \theta_{b}\right. \\
+\frac{r^{4} \alpha(\alpha-1)(\alpha-2)}{6 H^{3}} \cos ^{3} \theta_{b} \\
+\frac{a^{2}\left(r^{3} \sin ^{2} \theta_{b}-r x^{2}\right)}{\left.\left(r^{2} \sin ^{2} \theta_{b}+x^{2}\right)^{2}\right] d r} \\
=v_{\mathrm{eq}_{0}}+v_{\mathrm{eq}_{\mathrm{ws}}}+v_{\mathrm{eq}_{\mathrm{ts}} .}
\end{gathered}
$$

Equation (10) has been split into three components: $v_{\mathrm{eq}_{0}}$ due to the hub height wind speed, $v_{\mathrm{eq}}$ due to wind shear, and $v_{\mathrm{eq}}$ due to the tower shadow, where

$$
\begin{aligned}
& v_{\mathrm{eq}_{0}}= \frac{2 V_{h}}{3 s R^{2}} \sum_{b=1}^{3} \int_{r_{0}}^{R} r d r=V_{h}, \\
& v_{\mathrm{eq}_{\mathrm{ws}}}= \frac{2 V_{h}}{3 s R^{2}} \sum_{b=1}^{3} \int_{r_{0}}^{R}\left[r^{2}\left(\frac{\alpha}{H}\right) \cos \theta_{b}+\frac{r^{3} \alpha(\alpha-1)}{2 H^{2}} \cos ^{2} \theta_{b}\right. \\
&\left.+\frac{r^{4} \alpha(\alpha-1)(\alpha-2)}{6 H^{3}} \cos ^{3} \theta_{b}\right] d r \\
&= V_{h}\left[\frac{\alpha(\alpha-1)}{8}\left(\frac{R}{H}\right)^{2}\right. \\
& v_{\mathrm{eq}}= \frac{2 V_{h}}{3 s R^{2}} \sum_{b=1}^{3} \int_{r_{0}}^{R}\left[\frac{\alpha(\alpha-1)(\alpha-2)}{60}\left(\frac{R}{H}\right)^{3} \cos 3 \theta_{b}\right], \\
&= \frac{V_{h}}{3 R^{2}} \sum_{b=1}^{3}\left[\frac{\left.r^{3} \sin ^{2} \theta_{b}-r x^{2}\right)}{\left.\sin ^{2} \theta_{b}+x^{2}\right)^{2}}\right] d r \\
&\left.\ln \left(\frac{R^{2} \sin ^{2} \theta_{b}}{x^{2}}+1\right)-\frac{2 a^{2} R^{2}}{R^{2} \sin ^{2} \theta_{b}+x^{2}}\right] .
\end{aligned}
$$

Note that (12) and (13) have been simplified by assuming $r_{0}=0$. The resultant aerodynamic torque due to $v_{\mathrm{eq}}(t, \theta)$ can be then obtained by substituting $v_{\mathrm{eq}}(t, \theta)$ in (9) and simplifying

$$
T_{\text {aero }}(t, \theta)=\frac{1}{2} \frac{\rho A V_{h}^{3} C_{p}\left(\lambda_{0}\right)}{\omega_{\text {rotor }}}+\frac{\rho A V_{h} C_{p}\left(\lambda_{0}\right) R}{\lambda_{0}}\left[v_{\mathrm{eq}_{\mathrm{ws}}}+v_{\mathrm{eq}_{\mathrm{ts}}}\right] .
$$

Equation (14) is the complete torque equation representing aerodynamic torque due to kinetic energy in wind as well as torque due to tower shadow and wind shear and has been implemented for modeling. The aerodynamic torque module, shown in Figure 5 implements the classical torque equation, that is, first term in (14) as

$$
T_{\text {aero }}^{\text {classical }}=\frac{1}{2} \frac{\rho A V_{h}^{3} C_{p}\left(\lambda_{0}\right)}{\omega_{\text {rotor }}}
$$

The wind shear module implements the disturbance in torque due to wind shear, that is, the second term in (14) as

$$
T_{\text {aero }}^{\text {wind shear }}=\frac{\rho A V_{h} C_{p}\left(\lambda_{0}\right) R}{\lambda_{0}} v_{\mathrm{eq}_{\mathrm{ws}}} \text {. }
$$

The tower shadow module implements the disturbance in torque due to tower shadow, that is, the third term in (14) as

$$
T_{\text {aero }}^{\text {tower shadow }}=\frac{\rho A V_{h} C_{p}\left(\lambda_{0}\right) R}{\lambda_{0}} v_{\mathrm{eq}_{\mathrm{ts}}} .
$$

Modeling (14) into three separate modules gives the wind turbine model greater flexibility allowing tower shadow and wind shear to be studied separately, as will be demonstrated in Section 5. Also note that the tower shadow and wind shear modules input the wind turbine specifications $(H, x, a, \alpha)$ for calculating the torque oscillations due to $3 p$ effect, as shown in Figure 5. Few important points when modeling the above three modules are

(i) $C_{p}\left(\lambda_{0}\right)$ and $\lambda_{0}$ should be computed at the hub height wind speed $V_{h}$;

(ii) computation of $v_{\mathrm{eq}}$ and $v_{\mathrm{eq}}$ in (16) and (17) require instantaneous values of the three blade angles. The azimuthal angle of the first blade $\left(\theta_{b 1}\right)$ can be obtained by integrating rotor angular velocity. Integrator has to be reset once the first blade angle reaches $360^{\circ}$. The other two blade angles can be obtained by adding $120^{\circ}$ and $240^{\circ}$ to $\theta_{b 1}$, respectively;.

(iii) $v_{\mathrm{eq}}$ should be computed only when the individual blade is in the tower-shadow zone, as discussed in Section 3. For example, the first blade (reference blade) will be in the tower-shadow zone only when $\theta_{b 1}$ is between $90^{\circ}$ and $270^{\circ}$. A logical operator should be used so that when the first blade is outside the tower-shadow zone, contribution to $v_{\mathrm{eq}}$ from the first blade should be zero.

The total aerodynamic torque can be then obtained by summing up $T_{\text {aero }}^{\text {classical }}, T_{\text {aero }}^{\text {wind shear }}$, and $T_{\text {aero }}^{\text {tower shadow }}$, scaled by the gear ratio and used as an input to the drive-train model, as shown in Figure 5.

4.2. Mechanical Block. The mechanical block consisting of the wind turbine shaft, generator shaft, and gearbox has been modeled using a two-mass inertia representation, since the two-mass model is simpler to model and shows the dynamic response of the wind turbine generator. State-space equations governing the two-mass model have been detailed in $[11]$. 


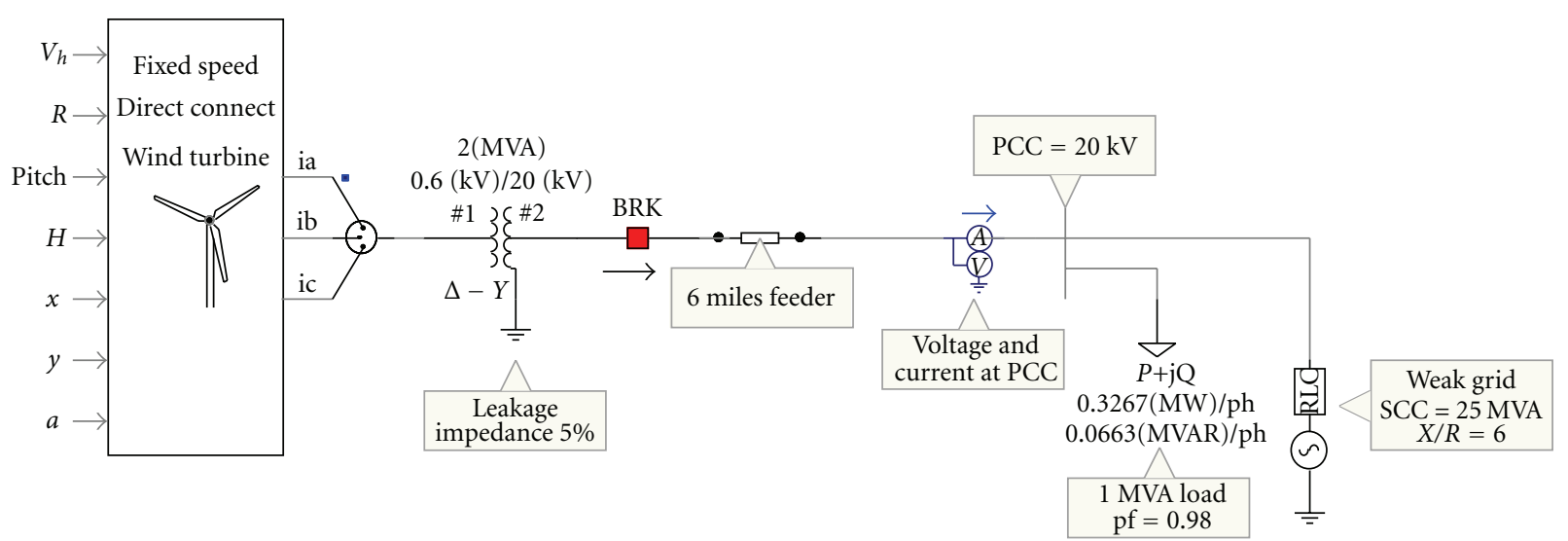

FIGURE 6: Fixed-speed wind turbine connected to the grid.

TABLE 2: Specifications of wind turbine model.

\begin{tabular}{llcc}
\hline Notation & Parameter & Value & Unit \\
\hline$R$ & Blade radius & 36 & $\mathrm{~m}$ \\
$H$ & Hub height & 80 & $\mathrm{~m}$ \\
$a$ & Tower radius & 2 & $\mathrm{~m}$ \\
$x$ & Blade origin from tower midline & 5 & $\mathrm{~m}$ \\
$\alpha$ & Wind shear component & 0.3 & \\
$\mathrm{GR}$ & Gear ratio & 70 & \\
$J_{\text {rot }}$ & Rotor moment of inertia & 1000 & $\mathrm{kgmm}$ \\
$J_{G}$ & Referred to the generator side & & \\
$P_{\text {gen }}$ & Generator moment of inertia & 80 & $\mathrm{kgmm}$ \\
$p$ & Generator-rated power & 1.5 & $\mathrm{MW}$ \\
$V_{\text {rated }}$ & Generator pole pairs & 3 & \\
$f_{n}$ & Generator-rated voltage & 0.6 & $\mathrm{kV}$ \\
\hline
\end{tabular}

4.3. Electrical Block. The main component of the electrical block is an induction generator. A fixed speed wind turbine requires squirrel-cage induction machine while variable speed wind turbines need a wound rotor induction machine [11].

4.4. Control Block. This block can be developed for adjusting the pitch angle in variable speed wind turbines or controlling reactive compensation devices to meet wind turbine reactive power demand. For a fixed-speed wind turbine, no control is required [11].

\section{Case Studies: Performance Evaluation of Wind Turbine Model}

The aforementioned wind turbine components are integrated to form a $1.5 \mathrm{MW}$ fixed speed wind turbine model. The numerical data set used for simulation of wind turbine model is listed in Table 2. The wind turbine is then connected to a weak grid via a 2-MVA $0.6 / 20 \mathrm{kV}$ delta-wye-grounded transformer with a leakage inductance of $5 \%$ and a 6 mile



Figure 7: Power curve of a 1.5 MW fixed speed wind turbine.

medium voltage cable [14]. The grid has been intentionally chosen to be weak so as to study the impact of tower shadow and wind shear on power quality. The grid short-circuit capacity (SCC) was selected to be $25 \mathrm{MVA}$, since the grid is considered electrically weak when [15]

$$
\frac{\mathrm{SCC}}{P_{n}}<20,
$$

where $P_{n}$ is the rated power of the wind turbine, that is, $1.5 \mathrm{MW}$ in this case. $X / R$ ratio of the grid is assumed to be 6. At the point of common coupling (PCC), a 1-MVA, 0.98 power factor load is connected. Figure 6 shows the complete system arrangement. Case studies presented in this section aim at evaluating the wind turbine model performance and demonstrate the analyses that can be done using this model. The simulation package used is PSCAD/EMTDC.

5.1. Performance of the Wind Turbine without $3 p$ Effect. The performance of the wind turbine without $3 p$ effect (tower shadow and wind shear modules disconnected) is studied to determine the rotor angular velocity at the rated wind speed. 

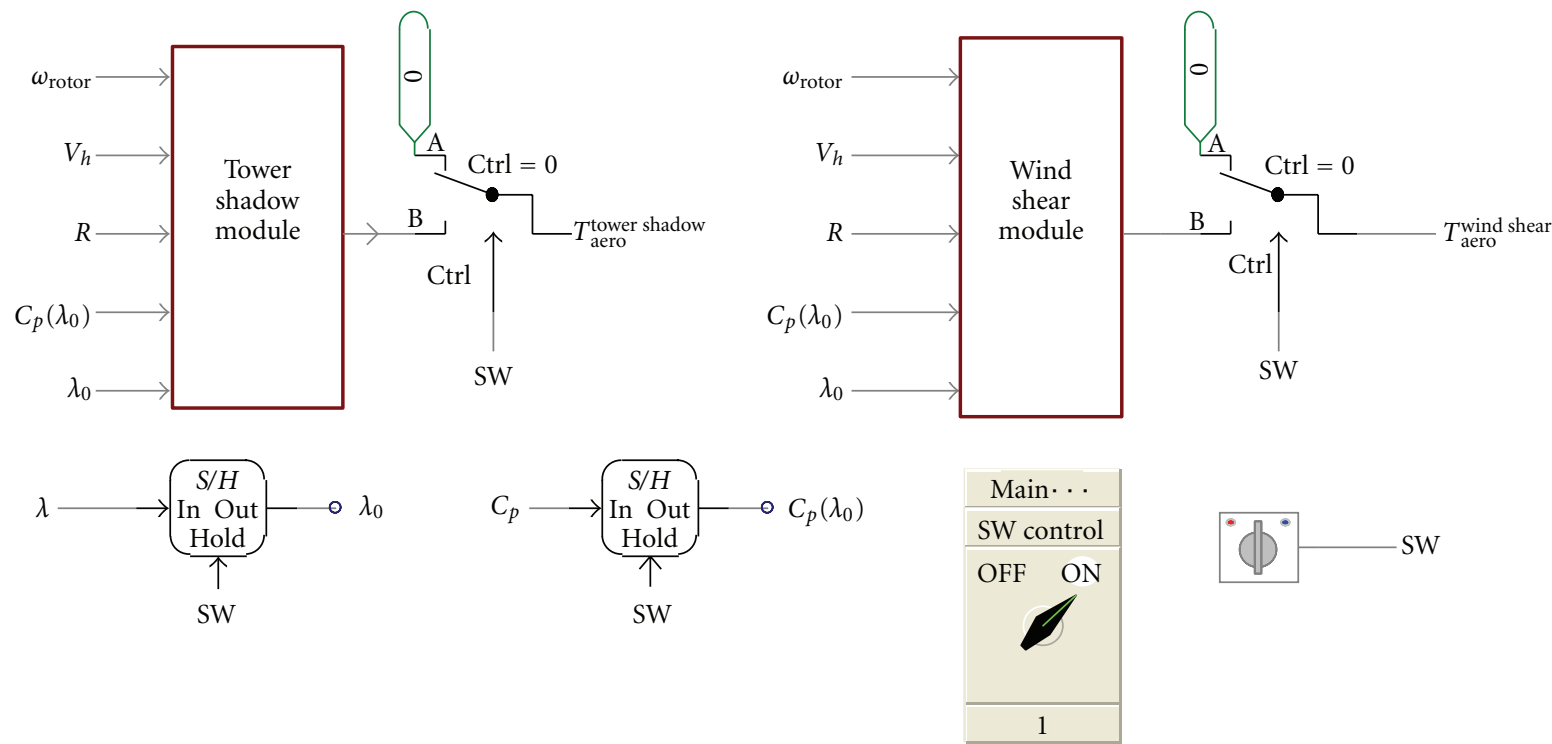

Figure 8: Sample/Hold circuit to hold $C_{p}\left(\lambda_{0}\right)$ and $\lambda_{0}$ at wind speed $V_{h}$.

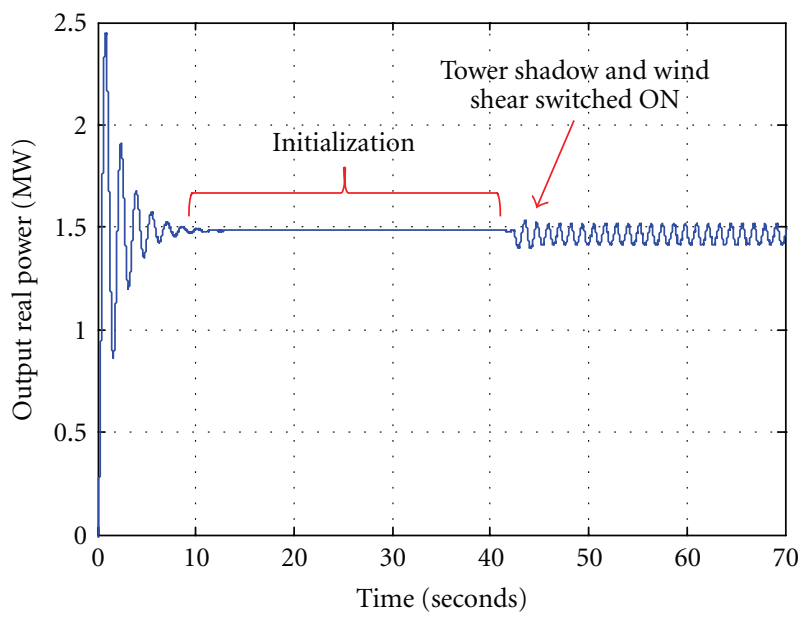

Figure 9: Output power with tower shadow and wind shear switched on.

The rated wind speed can be obtained from the power curve shown in Figure 7. The wind turbine model is subjected to hub height wind speed $\left(V_{h}\right)$ ranging from 0 to $20 \mathrm{~m} / \mathrm{s}$. Since this is a fixed speed wind turbine, pitch angle remains constant at $-6.15^{\circ}$. The rated wind speed is $15 \mathrm{~m} / \mathrm{s}$ and rated power is $1.5 \mathrm{MW}$. The rotor angular velocity $\omega_{\text {rotor }}$ is $1.8 \mathrm{rad} / \mathrm{s}$ or $0.286 \mathrm{~Hz}$.

\subsection{Performance of the Wind Turbine with $3 p$ Effect}

5.2.1. Initialization of the Wind Turbine Model. The wind turbine can be started at any wind speed above the cut-in speed. Initially, a switch SW disconnects the tower shadow and wind shear modules till steady-state is reached. Then SW is switched "ON." This initialization is necessary since $T_{\text {aero }}^{\text {wind shear }}$ and $T_{\text {aero }}^{\text {tower shadow }}$ require the values of $C_{p}\left(\lambda_{0}\right)$ and $\lambda_{0}$ at the hub height wind speed $V_{h}$. Sample/hold circuits are used in conjunction with switch SW such that when SW is switched "ON," the $\mathrm{S} / \mathrm{H}$ circuits hold the values of $C_{p}\left(\lambda_{0}\right)$ and $\lambda_{0}$, as illustrated in Figure 8. Depending on the simulation time step, the initialization step requires a few seconds, that is, 10 seconds in PSCAD/EMTDC.

5.2.2. Output Power from Wind Turbine. The wind turbine is subjected to rated $V_{h}$. After initialization, the wind shear and tower shadow modules are activated by toggling the switch $(\mathrm{SW}=1)$. The output power from the wind turbine starts to oscillate as soon as the tower shadow and wind shear modules are activated, as shown in Figure 9. An FFT block with fundamental frequency equal to rotational frequency of the blades ( $\omega_{\text {rotor }}=0.286 \mathrm{~Hz}$ ) is used to determine the frequency components present in the output power. As shown in Figure 10, FFT indicates the presence of a significant third harmonic, that is, $0.86 \mathrm{~Hz}$ (which is three times $\omega_{\text {rotor }}$ ), whose magnitude is $0.0516 \mathrm{MW}$.

5.3. Increase in Output Power due to $3 p$ Effect. The output power swings beyond the rated power (1.5 MW) when tower shadow and wind shear modules are switched "ON," as shown in Figure 9. This is counterintuitive since output power should decrease as the $3 p$ effect leads to a net decrease in the wind speed. Figure 11 shows the equivalent wind speed and aerodynamic torque scaled down to bring them on the same scale as the output power. As seen from the figure, a decrease in equivalent wind due to $3 p$ effect results in a corresponding decrease in torque. The output power, however, seems to peak at that time instant.

The reason for the output power swinging beyond the rated power was determined to be the transient response of the generator. The oscillations in torque continually disturb the system, that is, the generator is not allowed to reach steady state, which is why the output power is swinging above 


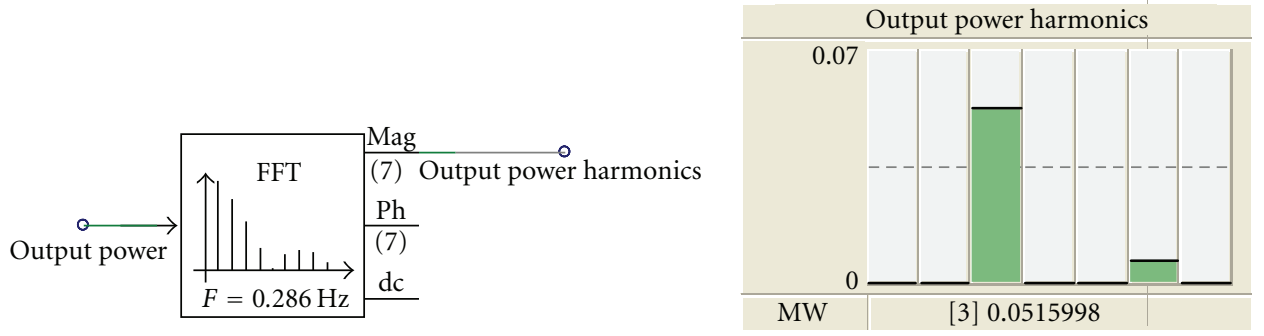

FIGURE 10: FFT indicating $3 p$ frequency.

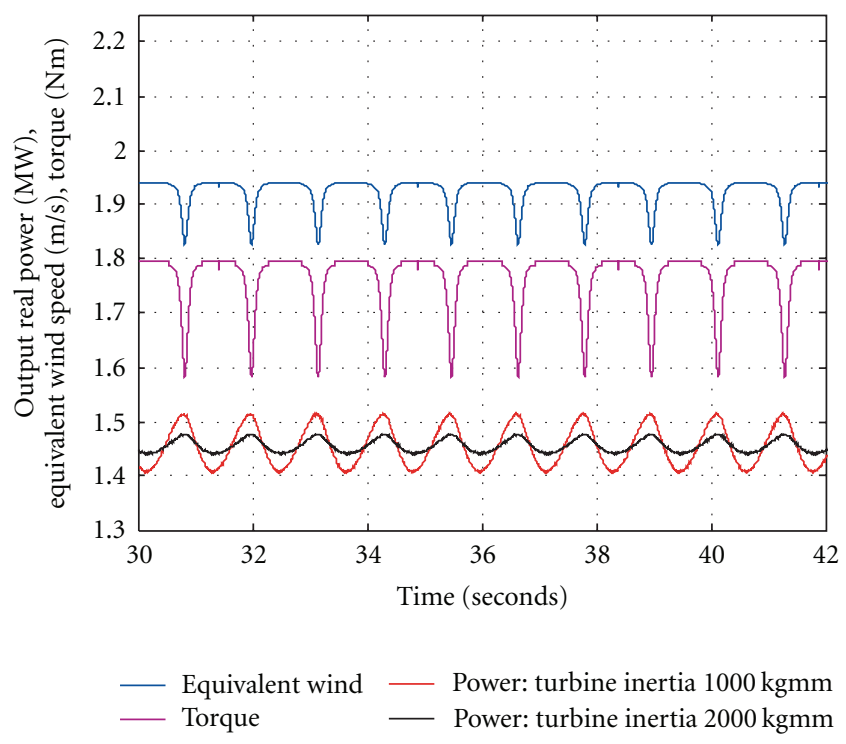

FIgURE 11: Equivalent wind, torque, and output power.

the rated power. To prove the above theory, the inertia of the turbine $J_{\text {rot }}$ was increased from $1000 \mathrm{kgmm}$ to $2000 \mathrm{kgmm}$, since inertia plays a significant role in controlling the transient response. Now, the $3 p$ oscillations in the output power does not swing beyond the rated power, as shown in Figure 11.

5.4. Impact of Wind Shear and Tower Shadow Individually on Output Power. This section demonstrates how the model can be used to study the impact of tower shadow and wind shear individually on the magnitude of output power oscillations. The wind turbine model is initialized by subjecting it to rated $V_{h}$ and then switch SW is used to activate the tower shadow module only. The output power oscillates between 1.528 MW and 1.429 MW, as shown in Figure 12. When switch SW activates the wind shear module only, the output power oscillates between 1.469 MW and 1.461 MW. The magnitude of the oscillations are very small, indicating that tower shadow effect has a more dominant impact on output power that wind shear. This is consistent with the analysis reported in [1].

5.5. Voltage at the PCC. Rms voltage was measured at PCC as shown in Figure 13. The voltage remains constant at $11.28 \mathrm{kV}$

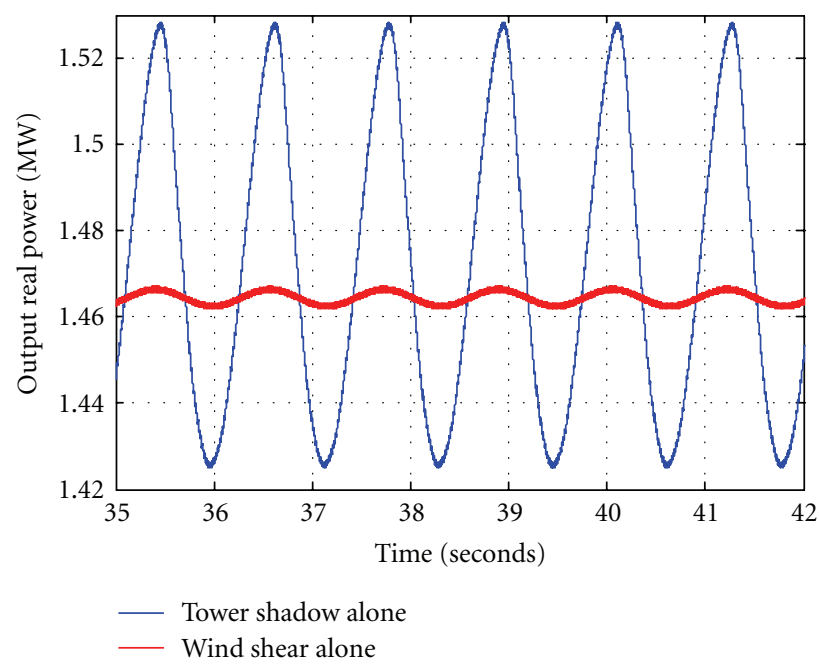

FIGURE 12: Magnitude of $3 p$ oscillations due to tower shadow and wind shear individually.

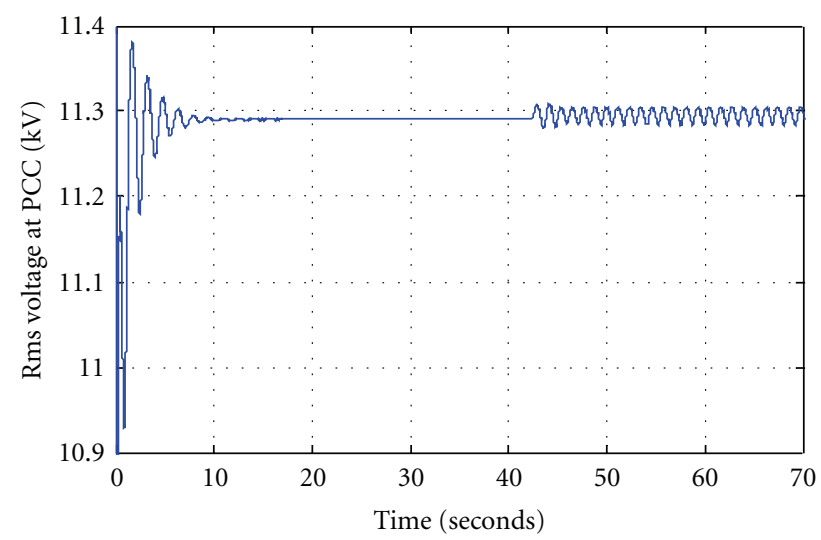

Figure 13: Phase an RMS voltage.

during the initialization of the model. Once the tower shadow and wind shear modules are switched "ON," the rms voltage shows the presence of the $3 p$ oscillations. These fluctuations in system rms voltage may cause consumer annoyance and complaint and are known as voltage flicker. The usual method of expressing flicker is similar to that of voltage modulation, that is, change in voltage with respect to the average voltage over a certain time period as [6]

$$
\% \text { Voltage Modulation }=\frac{V_{\max }-V_{\min }}{V_{0}} .
$$




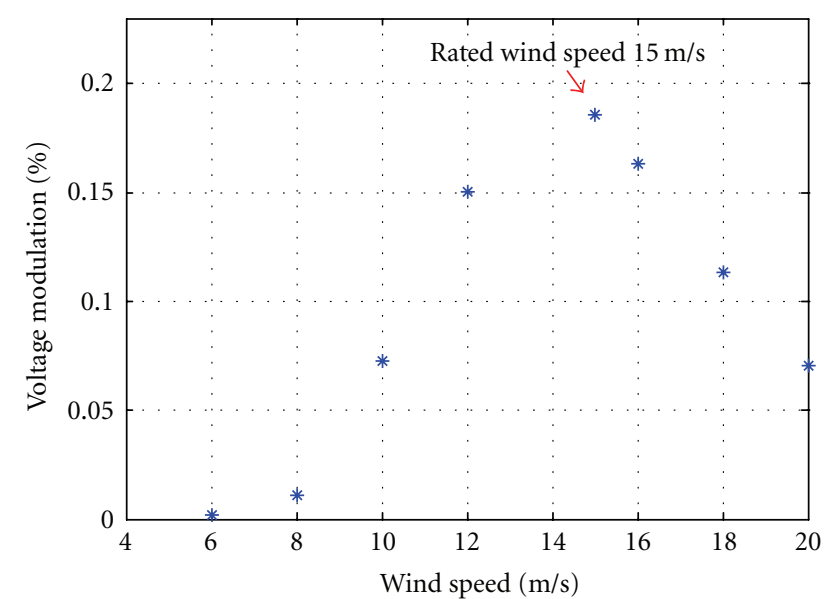

Figure 14: Voltage flicker variation with $V_{h}$.

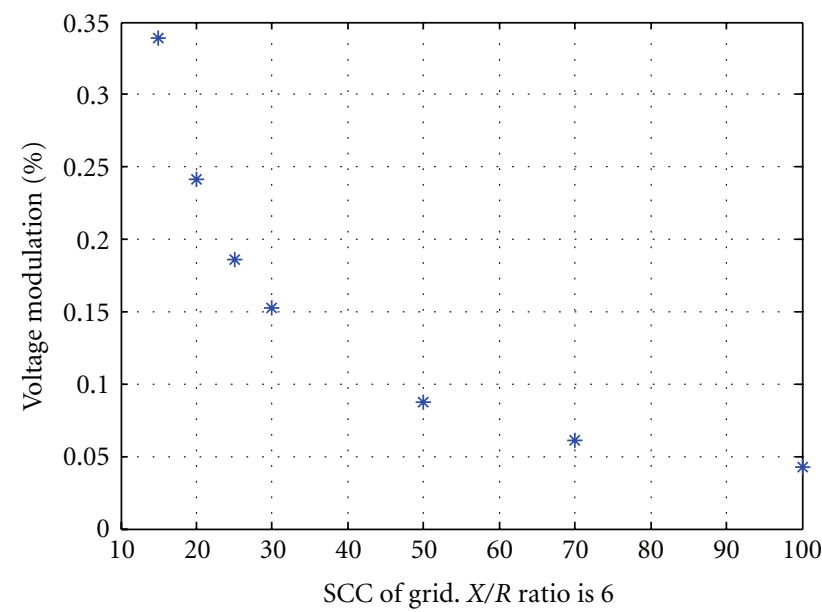

FIGURE 15: Variation of voltage flicker with SCC. $X / R$ ratio of grid is 6 .

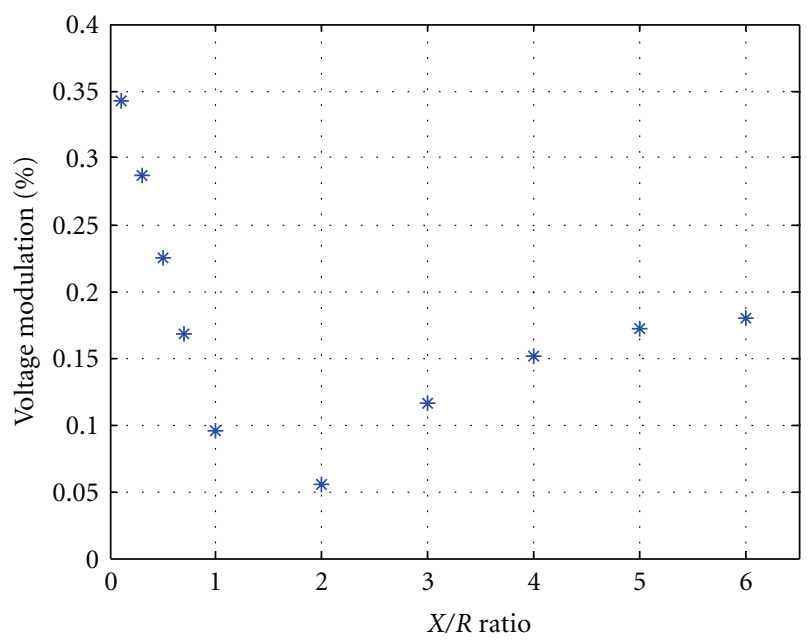

FIGURE 16: Variation of voltage flicker with $X / R$ ratio. Grid SCC is 25 MVA.

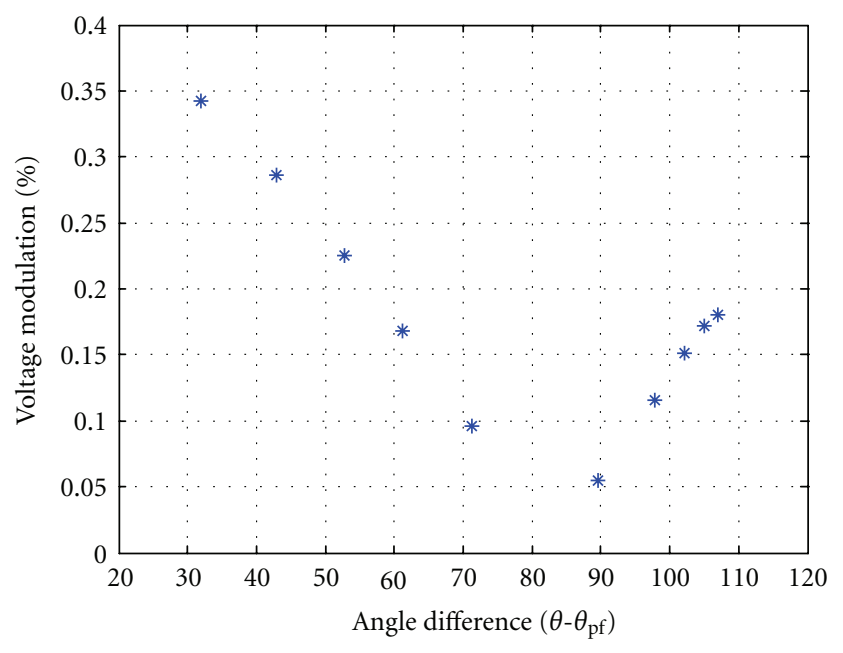

FIgURE 17: Variation of voltage flicker with $\theta-\theta_{\mathrm{pf}}$.

Here $V_{\max }$ and $V_{\min }$ are the maximum and minimum values of modulated signal while $V_{0}$ is the average value of normal operating voltage. Using (19), the voltage flicker (expressed in percentage of voltage modulation) was calculated to be $0.186 \%$. This is below the threshold of objection. However, in a wind farm, if many wind turbine blades synchronize, the magnitude of voltage flicker would be severe [2].

5.6. Factors Affecting Voltage Flicker. Voltage flicker due to tower shadow and wind shear depends on $[4,5]$

(i) hub height wind speed $V_{h}$;

(ii) grid short-circuit capacity;

(iii) grid impedance angle or $X / R$ ratio.

To investigate how these parameters influence voltage flicker, they are varied one at a time. The parameters used in Figure 6 will be used as the base case, that is, $V_{h}, \mathrm{SCC}$, and $X / R$ ratio of grid are $15 \mathrm{~m} / \mathrm{s}, 25 \mathrm{MVA}$, and 6, respectively. Turbulence intensity and loads connected at the PCC also affect voltage flicker, however, they are not studied in this section.

5.6.1. Impact of $V_{h}$ on Voltage Flicker. The wind turbine was subjected to wind speeds ranging from cut-in to cutout speed and the voltage flicker at each wind speed was calculated using (19). As seen from Figure 14, voltage flicker increases almost linearly with wind speed till the rated wind speed is reached. For $V_{h}$ greater than the rated speed, voltage flicker starts decreasing due to the stall regulation of the rotor which significantly reduces the turbulence-induced fluctuations. Hence, voltage flicker is maximum at the rated wind speed or, in other words, voltage flicker is maximum when wind power output is maximum.

5.6.2. Impact of Grid Short-Circuit Capacity (SCC) on Voltage Flicker. The SCC or strength of the grid is varied at each simulation. Figure 15 illustrates the approximately inversely proportionally relationship with short-circuit capacity (SCC) of 
grid. Higher the SCC, stronger the grid is, and hence voltage flicker is minimum.

5.6.3. Impact of Network Impedance Angle (X/R Ratio) on Voltage Flicker. In this subsection, $X / R$ ratio of the grid is varied from 1 to 7 while the grid SCC is kept constant at 25 MVA. As shown in Figure 16, minimum voltage flicker is obtained for an $X / R$ ratio of 2 .

The $V$-shaped curve can be explained by considering voltage change $(\Delta U)$ across the grid impedance $(R$ and $X)$ as [5]

$$
\Delta U=\frac{P R \cos \left(\theta-\theta_{\mathrm{pf}}\right)}{U_{g} \cos \theta_{\mathrm{pf}} \cos \theta} .
$$

Here $P$ is the real power produced by the wind turbine, $\theta$ is the network impedance angle, $\theta_{\mathrm{pf}}$ is the power factor at which the wind turbine is operating while $U_{g}$ represent the voltage at the PCC. From (20), the determining factor for minimizing the voltage drop is $\cos \left(\theta-\theta_{\mathrm{pf}}\right)$. When $\left(\theta-\theta_{\mathrm{pf}}\right)$ approaches $90^{\circ}$, voltage flicker is minimum, as shown in Figure 17 . Since $\theta_{\mathrm{pf}}$ is approximately $26^{\circ}$ in the simulation case, minimum voltage flicker occurs for $\theta=64^{\circ}$ or $X / R=2$.

\section{Conclusion}

This paper presents a detailed model of a fixed speed wind turbine with an upwind rotor. The modeling includes a detailed representation of tower shadow and wind shear modules which are often approximated or neglected in existing models. The model will allow the user to input wind turbine specifications and observe how those parameters will directly affect the magnitude of $3 p$ oscillations. Another advantage is that the model is flexible, allowing the user to study tower shadow and wind shear individually. Case studies have been carried out to use this model for studying the integration of wind turbine to the grid and analyzing voltage flicker at the PCC. The results are consistent with those reported in the literature and hence the model performs as expected. In addition, the model can also be used to study the mitigation of $3 p$ effect and expanded to include power and pitch controllers to suit other studies involving variable speed wind turbines.

\section{References}

[1] D. Dolan and P. Lehn, "Simulation model of wind turbine $3 p$ torque oscillations due to wind shear and tower shadow," IEEE Transactions on Energy Conversion, vol. 21, no. 3, pp. 717-724, 2006.

[2] D. McSwiggan, T. Littler, D. J. Morrow, and J. Kennedy, "A study of tower shadow effect on fixed-speed wind turbines," in Proceedings of the 43rd International Universities Power Engineering Conference, (UPEC '08), pp. 1-5, September 2008.

[3] J. F. Manwell, J. G. McGowan, and A. L. Rogers, Wind Energy Explained: Theory, Design and Application, Wiley, 2010.

[4] M. Papadopoulos, S. Papathanassiou, S. Tentzerakis, and N. Boulaxis, "Investigation of the flicker emission by grid connected wind turbines," in Proceedings of the 8th International
Conference on Harmonics and Quality of Power, vol. 2, pp. 1152-1157, October 1998.

[5] T. Sun, Z. Chen, and F. Blaabjerg, "Flicker study on variable speed wind turbines with doubly fed induction generators," IEEE Transactions on Energy Conversion, vol. 20, no. 4, pp. 896-905, 2005.

[6] R. C. Dugan, M. F. McGranaghan, S. Santoso, and H. W. Beaty, Electrical Power Systems Quality, McGraw-Hill, 2nd edition, 2003.

[7] H. Amaris, C. Vilar, J. Usaola, and J. Rodriguez, "Frequency domain analysis of flicker produced by wind energy conversions systems," in Proceedings of the 8th International Conference on Harmonics and Quality of Power, vol. 2, pp. 1162-1167, October 1998.

[8] H. Sharma, S. Islam, T. Pryor, and C. V. Nayar, "Power quality issues in a wind turbine driven induction generator and diesel hybrid autonomous grid," Journal of Electrical and Electronics Engineering, vol. 21, no. 1, pp. 19-25, 2001.

[9] C. Sao, D. Dolan, and P. Lehn, "Voltage flicker model of wind turbine generators due to wind shear and tower shadow," International Council on Large Electric Systems, no. 20, 2006.

[10] P. Sørensen, A. D. Hansen, and P. A. C. Rosas, "Wind models for simulation of power fluctuations from wind farms," Journal of Wind Engineering and Industrial Aerodynamics, vol. 90, no. 12-15, pp. 1381-1402, 2002.

[11] S. Santoso and H. T. Le, "Fundamental time-domain wind turbine models for wind power studies," Renewable Energy, vol. 32, no. 14, pp. 2436-2452, 2007.

[12] M. R. Elkinton, A. L. Rogers, and J. G. McGowan, "An investigation of wind-shear models and experimental data trends for different terrains," Wind Engineering, vol. 30, no. 4, pp. 341-350, 2006.

[13] S. C. Gupta, Fluid Mechanics and Hydraulic Machines, Dorling Kindersley, 2006.

[14] S. Heier, Grid Integration of Wind Energy Conversion Systems, John Wiley \& Sons, 2006.

[15] A. Abdelaziz, A. Mohamed, L. Khalid, and B. Khalid, "Added value of power control in improving the integration of wind turbines in weak grid conditions," Energy and Power Engineering, vol. 2, no. 4, pp. 230-237, 2010. 

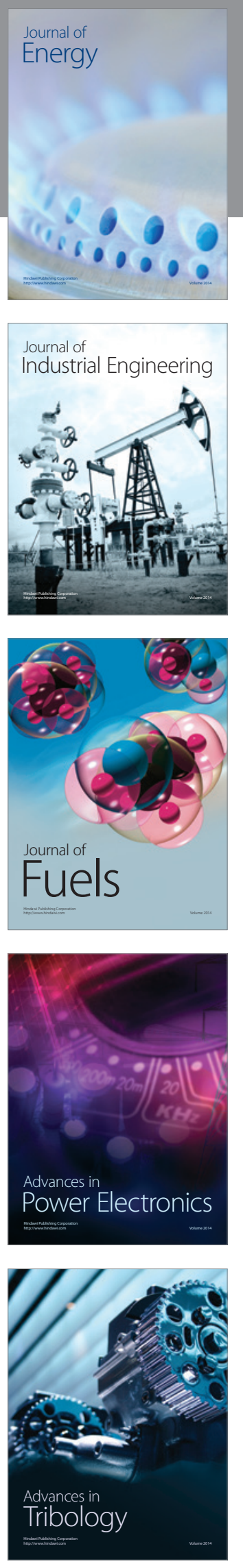


The Scientific World Journal

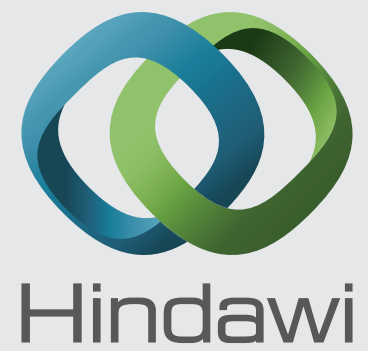

Submit your manuscripts at http://www.hindawi.com


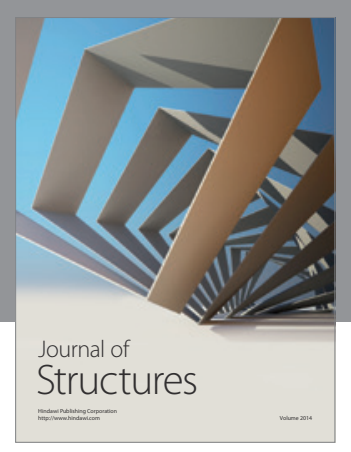

Rotating
Mechinery
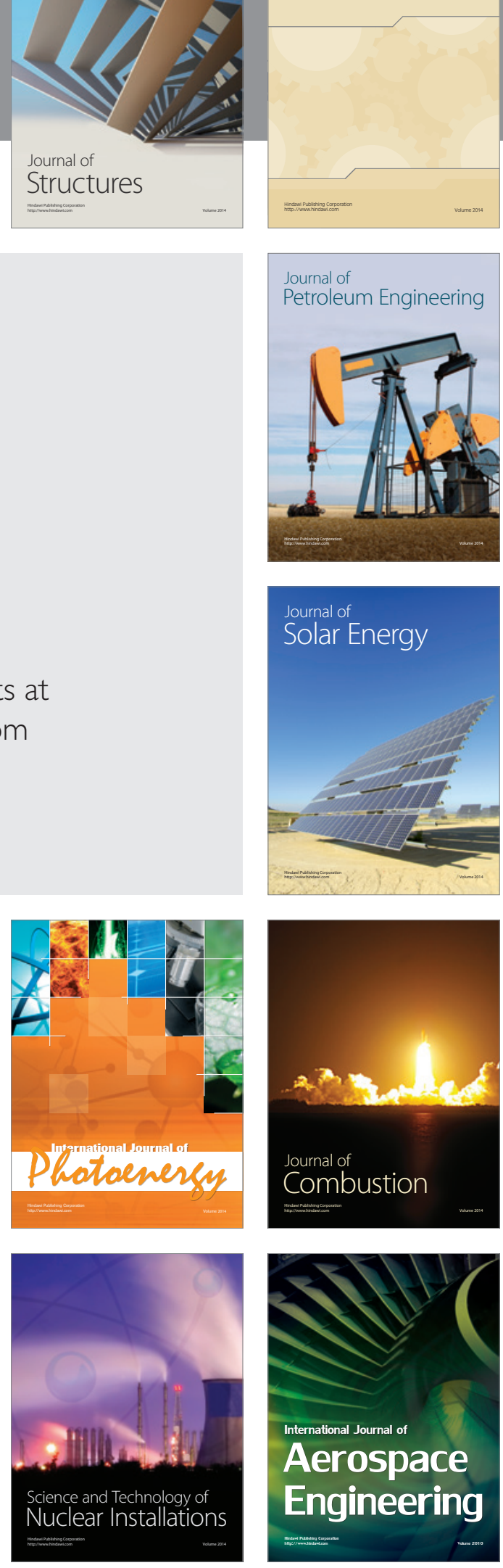